\title{
Indirect Chemiluminescence-based Determination of Catecholamines in Pharmaceutical Formulations by Furandicarboxylate Derivative as a Novel Blue Fluorescer in Peroxyoxalate- $\mathrm{H}_{2} \mathrm{O}_{2}$ System
}

\author{
Mohammad Javad ChaichI, $* \dagger$ Tahereh KhaJvand, ${ }^{* \dagger}$ Jalil Mehrzad, ${ }^{* *}$ Sakineh AsgharI, $*$ and \\ Mohammad QANDALEE*** \\ *Faculty of Chemistry, University of Mazandaran, Babolsar 4741695447, Iran \\ **Department of Pathobiology, Sections Immunology and Biotechnology, Faculty of Veterinary Medicine, \\ Institute of Biotechnology, Ferdowsi University of Mashhad, Mashhad, Iran \\ ***Department of Biology, Garmsar Branch, Islamic Azad University, Garmsar, Iran
}

\begin{abstract}
A novel, simple, cheap, and high sensitivity batch chemiluminescent method for the determination of catecholamine drugs, epinephrine (E), dopamine (DA) and methyldopa (MD) at microgram levels in pharmaceutical formulations is described. The method is based on a chemiluminescence (CL) system arising from the reaction of bis(2,4,6-trichlorophenyl) oxalate (TCPO) with $\mathrm{H}_{2} \mathrm{O}_{2}$ in the presence of a novel fluorescer, furandicarboxylate, and is proposed as a new analytical method for the determination of catecholamines. The method is based on the inhibition of CL emission by DA and its enhancement by E and MD. Under optimal conditions, good linear ranges were obtained, $0.5-12.7,0.06-1.83$ and $0.069-3.52 \mu \mathrm{g} / \mathrm{mL}$ with detection limits of $0.30,0.03$ and $0.04 \mu \mathrm{g} / \mathrm{mL}(S / N=3)$ for DA, E and MD, respectively. Moreover, a pooled-intermediate model was used to determine the kinetic parameters of CL with and without catecholamines and a possible CL mechanism was discussed.
\end{abstract}

Keywords Peroxyoxalate chemiluminescence, catecholamine pharmaceuticals, furandicarboxylate derivative, kinetic parameters, $\mathrm{H}_{2} \mathrm{O}_{2}$

(Received February 13, 2013; Accepted June 4, 2013; Published August 10, 2013)

\section{Introduction}

Catecholamines (CAs) are compounds that consist of amines attached to a benzene ring bearing two hydroxyl groups (catechol). The main sites of catecholamine production are the brain, chromaffin cells of the adrenal medulla and the sympathetic neurons. ${ }^{1}$ CAs are important neurotransmitters that play critical roles in the functioning of the brain and the signal transduction of the nervous system. Abnormal levels of CAs in the human body may signal the symptoms of certain diseases. ${ }^{2}$ Because of the significance of CAs in clinical diagnosis and medical treatment, rapid and sensitive determination of these compounds in biological samples and pharmaceutical formulations is therefore very important.

A variety of techniques, such as spectrophotometry, ${ }^{3,4}$ fluorometry, ${ }^{5-8}$ electrochemistry ${ }^{5,9,10}$ and tandem mass spectrometry ${ }^{11}$ have been utilized for the detection of CAs. However, some of these methods lack sensitivity and selectivity or require derivation steps or sophisticated instruments. Another attractive method for sensitive detection of CAs is based on

† To whom correspondence should be addressed.

E-mail: jchaichi@yahoo.com (M. J. C.); khajvand@gmail.com (T. K.) chemiluminescence (CL), which is usually coupled with flow injection (FI), ${ }^{12-19}$ high-performance liquid chromatography $(\text { HPLC) })^{20,21}$ or capillary electrophoresis (CE).22-25 The advantages of the CL technique include superb sensitivity, wide dynamic range, simple instrumentation and easy automation.

The peroxyoxalate chemiluminescence (PO-CL) is known as the most efficient non-enzymatic CL reaction, with a quantum yield as high as $25 \%$. The mechanism of the reaction of an oxalic ester, such as bis(2,4,6-trichlorophenyl) oxalate (TCPO), with $\mathrm{H}_{2} \mathrm{O}_{2}$ and a fluorescent compound was first summarized by Rauhut. ${ }^{26}$ Numerous subsequent reports concerning the PO-CL mechanism followed. ${ }^{27-29}$ However, no direct evidence about the intermediate had been proven until now. It is believed that the light emission can be ascribed to the chemically induced electron exchange luminescence (CIEEL) mechanism. Until now, there have been only a few investigations of the CIEEL mechanism in PO-CL. ${ }^{30-32}$ Continual study for a complete explanation of the PO-CL mechanism is still under exploration.

The generally accepted explanation of the reaction mechanism is illustrated in Scheme 1. The reaction includes three steps: (a) $\mathrm{H}_{2} \mathrm{O}_{2}$ and TCPO react and produce an active intermediate, postulated as 1,2-dioxetanedione; (b) 1,2-dioxetanedione transfers as much as $106 \mathrm{kcal} / \mathrm{mol}$ of energy to a suitable fluorescer to form the first singlet excited state; and (c) once excited, the excited fluorescer emits its characteristic light as it 


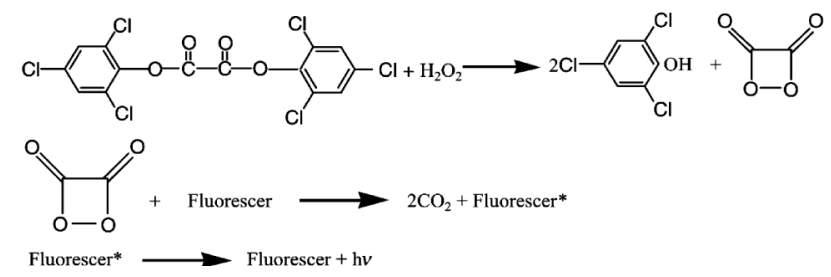

Scheme 1 Generally accepted understanding of the CIEEL mechanism in PO-CL.

performs fluorescence detection.

Based on this understanding, the overall quantum yield $\left(\Phi_{\mathrm{CL}}\right)$ of PO-CL reactions is directly dependent on the fluorescence quantum yield of the fluorescer. ${ }^{30,31}$ Thus, it is pertinent to design and synthesize new fluorescent fluorescer for sensitive determination of CAs. In recent years, we have studied the PO-CL reaction of several fluorescer in the presence of a suitable basic catalysts, such as sodium salicylate or imidazole. ${ }^{33-36}$ In this work we propose a novel highly fluorescent fluorescer di(ethyl)-2-(tert-butylamino)-5-biphenyl3,4-furandicarboxylate for PO-CL detection of CAs.

In this paper, we found that the CL emission of the TCPO$\mathrm{H}_{2} \mathrm{O}_{2}$-fluorescer (furandicarboxylate) system was greatly inhibited by dopamine (DA) and enhanced by epinephrine (E) and methyldopa (MD). Hereby, we reported the successful PO$\mathrm{CL}$ detection for the first time without the need for fluorescence labeling reaction of CAs. The proposed PO-CL method should become an alternative sensitive and selective method for the determination of CAs.

\section{Experimental}

\section{Reagents}

All chemical compounds were reagent-grade and purchased from Fluka Chemical Co. (CH-9470, Buchs, Switzerland) and used as received without further purification. Fluorescer di(ethyl)-2-(tert-butylamino)-5-biphenyl-3,4-furandicarboxylate was synthesized and purified in our laboratories, as described below. We described in detail the preparation of polyfunctionalized furan ring by reaction of alkyl isocyanides 1 with dialkyl acetylenedicarboxylate 2 in the presence of transcinnamaldehyde 3 . This three component reaction produces highly functionalized furan 4 in fairly good yields. The yield of reaction for production of the furan derivative was about $65 \%$ (Scheme 2). ${ }^{37}$

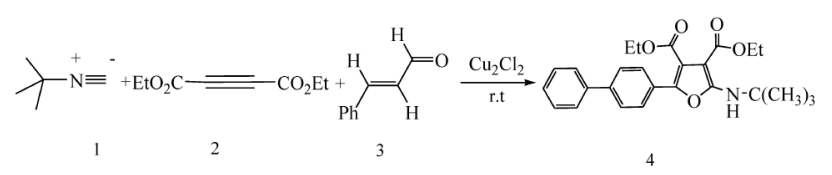

Scheme 2 Synthesis of di(ethyl)-2-(tert-butylamino)-5-biphenyl-3,4furandicarboxylate.

\section{Sample preparation}

Without any pretreatment, $2 \mathrm{~mL}$ injection sample was diluted to $100 \mathrm{~mL}$ with methanol and further diluted to the working range of the determination of DA and E, then analyzed according to the procedure described below. First, MD tablets were peeled off. Five gram samples were carefully ground, and then a $1.5 \mathrm{-g}$ sample was accurately weighed and extracted with $10 \mathrm{~mL}$ methanol at room temperature for $24 \mathrm{~h}$. The extracts were filtered through the same type of filter for three filtrations, followed by centrifugation for $10 \mathrm{~min}$ at $5000 \mathrm{rpm}$. The supernatant was transferred to a $50-\mathrm{mL}$ volumetric flask and adjusted to mark with methanol. This solution was further diluted with methanol appropriately so that the final concentration was within the working range. Sample solution was filtered through a $0.22-\mu \mathrm{m}$ membrane prior to injection.

\section{Apparatus}

The CL reaction was monitored by means of a homemade apparatus equipped with a Model BPY47 photocell (Leybold, Huerth, Germany). The apparatus was connected to a personal computer via a suitable interface (Micropars, Tehran, Iran). Experiments were carried out with magnetic stirring (500 rpm) in a light-tight flat-bottom glass cell of $15 \mathrm{~mm}$ diameter at $25^{\circ} \mathrm{C}$. CL intensity was recorded as a function of time, the time resolution of the apparatus was $0.6 \mathrm{~s}$ and $\mathrm{CL}$ intensity was reported in relative arbitrary units (a.u.).

Fluorescence and UV-vis spectra were recorded on LS-3B fluorescence (Perkin-Elmer) and CE 5501 UV-vis spectrophotometers (5000 series, England), respectively.

\section{Procedure}

Solution $I$ was made by mixing $1.0 \mathrm{~mL}$ of TCPO (various concentrations in ethyl acetate), $0.5 \mathrm{~mL}$ of fluorescer (various concentrations in ethyl acetate), $50 \mu \mathrm{L}$ CAs (various concentrations in methanol) or $50 \mu \mathrm{L}$ methanol and $1.5 \mathrm{~mL}$ of ethyl acetate. Solution II contained $2 \mathrm{~mL}$ of $\mathrm{H}_{2} \mathrm{O}_{2}$ (various concentrations) and the $1.0 \mathrm{~mL}$ of sodium salicylate (various concentrations) in methanol. Solution $I$ was transferred into the instrument quartz cuvette via polypropene syringes. Then $100 \mu \mathrm{L}$ of solution II was injected into the quartz cuvette and the CL profile was recorded soon after mixing.

In preliminary experiments, it was found that the addition of a few drops of the stock solution of $\mathrm{H}_{2} \mathrm{O}_{2}$ to an ethyl acetate solution containing TCPO and fluorescer in the presence of a suitable catalyst such as sodium salicylate (SS) resulted in a very intense blue emission. A decrease in the CL intensity was observed when a solution containing DA was present in the cell. On the other hand, an increase in the CL intensity was observed when a solution containing E or MD was present in the cell. This decrease and increase was evaluated in relation to the original CL emission corresponding to a blank, and it was found to be proportional to the $\mathrm{DA}, \mathrm{E}$ and $\mathrm{MD}$ concentrations $(\triangle C L)$. The value of $\triangle C L=\left(C L_{0}-\mathrm{CL}\right)$ showed the effect of CAs on the CL intensity of TCPO- $\mathrm{H}_{2} \mathrm{O}_{2}$-fluorescer CL system, where $C L_{0}$ stands for the signal in the absence of CAs and $C L$ stands for the signal in the presence of CAs, which was used for quantitative analysis of CAs.

\section{Results and discussion}

\section{Effect of CAs on the TCPO- $\mathrm{H}_{2} \mathrm{O}_{2}$-fluorescer-SS CL reaction}

Kinetic profiles of TCPO- $\mathrm{H}_{2} \mathrm{O}_{2}$-fluorescer-SS CL reaction in the presence and absence of $3.3 \times 10^{-2} \mathrm{mmol} / \mathrm{L} \mathrm{DA}, 5.0 \times$ $10^{-3} \mathrm{mmol} / \mathrm{L} \mathrm{E}$ and MD are shown in Fig. 1. It can be seen that the CL signal markedly increased when solutions contained $\mathrm{E}$ and $\mathrm{MD}$, however, the CL signal decreased in the presence of DA. Therefore, it may be concluded that E and MD played a role as an enhancer and DA played a role as a quencher in the $\mathrm{CL}$ reaction. Furthermore, the $\triangle C L$ intensity was proportional to the concentration of CA compounds. Therefore, a new CL method could be established to assay DA, E and MD. 


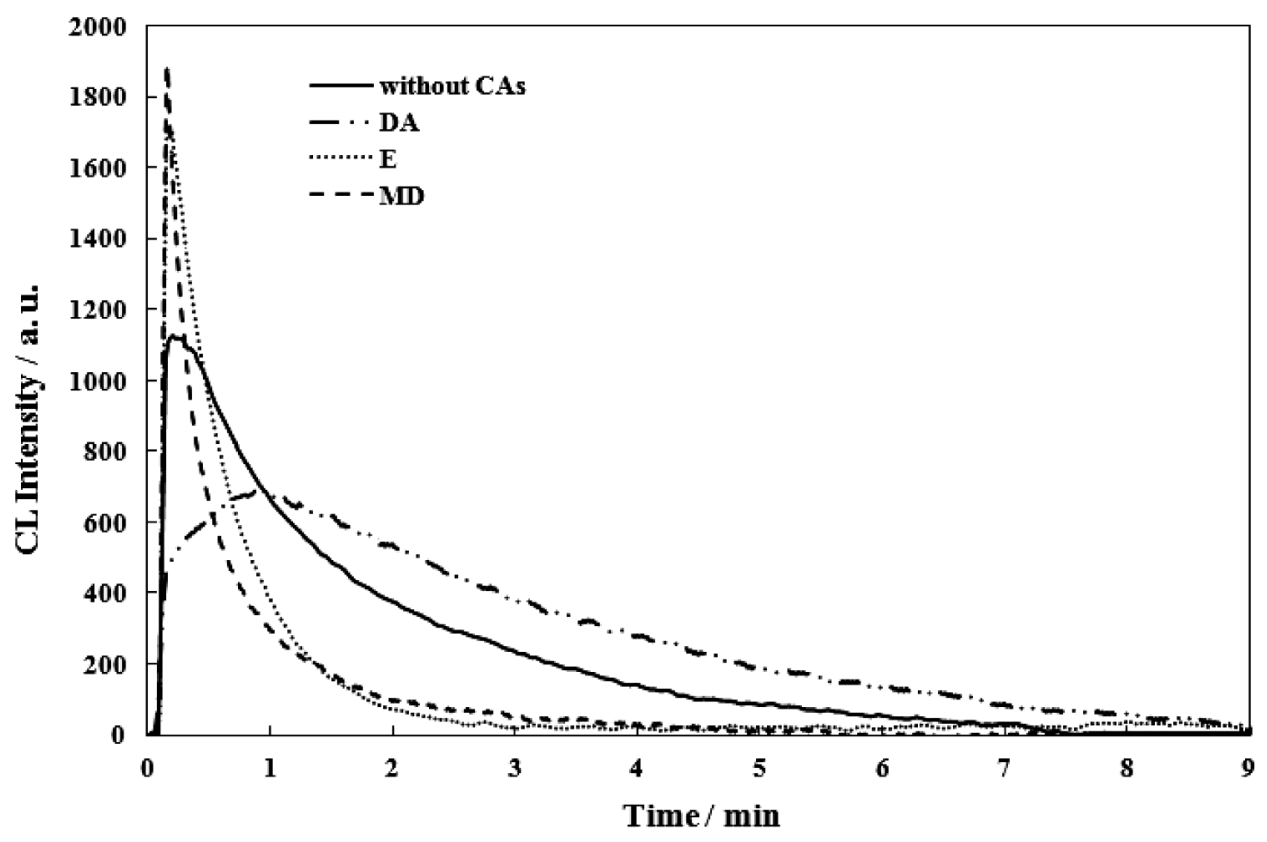

Fig. 1 Time course of the kinetic profile of the TCPO- $\mathrm{H}_{2} \mathrm{O}_{2}$-fluorescer-SS system after mixing of $2.5 \mathrm{mmol} / \mathrm{L} \mathrm{TCPO}, 13 \mathrm{mmol} / \mathrm{L} \mathrm{H}_{2} \mathrm{O}_{2}, 0.8 \mathrm{mmol} / \mathrm{L} \mathrm{SS}, 3.2 \mathrm{mmol} / \mathrm{L}$ fluorescer, $3.3 \times 10^{-2} \mathrm{mmol} / \mathrm{L} \mathrm{DA}$, $5.0 \times 10^{-3} \mathrm{mmol} / \mathrm{L} \mathrm{E}$ and $\mathrm{MD}$.
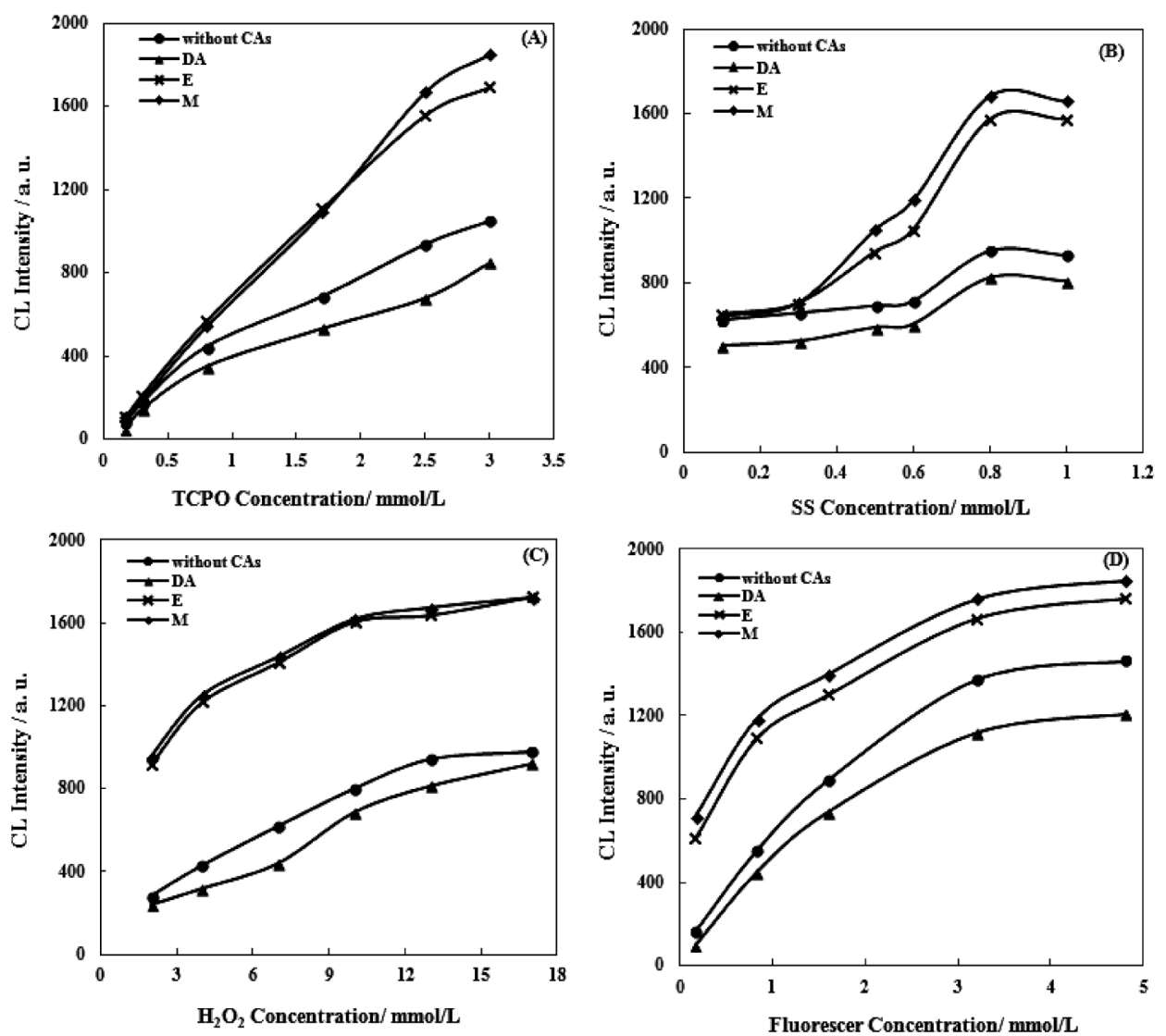

Fig. 2 Effects of the reactant conditions on the TCPO- $\mathrm{H}_{2} \mathrm{O}_{2}$-fluorescer-SS system in the absence and presence of $1.0 \mathrm{mmol} / \mathrm{L}$ CAs. (A) Effects of TCPO concentration: $10 \mathrm{mmol} / \mathrm{L} \mathrm{H}_{2} \mathrm{O}_{2}, 3.0 \mathrm{mmol} / \mathrm{L}$ fluorescer, $0.5 \mathrm{mmol} / \mathrm{L} \mathrm{SS}$. (B) Effects of SS concentration: $2.5 \mathrm{mmol} / \mathrm{L} \mathrm{TCPO}, 10 \mathrm{mmol} / \mathrm{L} \mathrm{H}_{2} \mathrm{O}_{2}$, $3.0 \mathrm{mmol} / \mathrm{L}$ fluorescer. (C) Effects of $\mathrm{H}_{2} \mathrm{O}_{2}$ concentration: $2.5 \mathrm{mmol} / \mathrm{L}$ TCPO, $3.0 \mathrm{mmol} / \mathrm{L}$ fluorescer, $0.8 \mathrm{mmol} / \mathrm{L} \mathrm{SS}$. (D) Effects of fluorescer concentration: $2.5 \mathrm{mmol} / \mathrm{L} \mathrm{TCPO}, 13 \mathrm{mmol} / \mathrm{L} \mathrm{H}_{2} \mathrm{O}_{2}$, $0.8 \mathrm{mmol} / \mathrm{L} \mathrm{SS}$. 


\section{Optimization of $P O-C L$ system conditions}

As expected, the intensity of the PO-CL emission was found to be affected by the initial concentration of the reactants. ${ }^{27-31,33-36}$ The CL conditions for the determination of CAs were optimized using the PO-CL system described in the experimental section. Optimum conditions were selected by monitoring CL intensity for the peaks of CAs. The key parameters optimized were TCPO, sodium salicylate, $\mathrm{H}_{2} \mathrm{O}_{2}$ and fluorescer concentrations. The influence of all of these studied variables on the CL intensity is shown in Fig. 2 and the selected optimum values are summarized in Table 1.

The influence of TCPO concentration on the CL reaction was investigated in the interval of $0.17-3 \mathrm{mmol} / \mathrm{L}$. The $\mathrm{CL}$ intensity increased with increasing TCPO concentration, so $2.5 \mathrm{mmol} / \mathrm{L}$ was selected as the optimum. ${ }^{35,36}$ The effects of different concentrations of SS on CL intensity were examined in the interval of $0.1-1 \mathrm{mmol} / \mathrm{L}$. The CL intensity increased with increasing concentrations of SS until $0.8 \mathrm{mmol} / \mathrm{L}$, but further increases in SS concentration caused a decrease in CL intensity. This is most probably due to the quenching effect of the SS at higher concentrations, which begins to decompose the reactive intermediate, 1,2-dioxetanedione, and hence reduces the PO-CL light. ${ }^{36}$ The concentration of hydrogen peroxide was studied in the interval of $2-17 \mathrm{mmol} / \mathrm{L}$. From a value of $13 \mathrm{mmol} / \mathrm{L}$, no enhancement of the emission was observed, so this was selected as the optimum concentration. The influence of fluorescer concentration on the PO-CL intensity was studied in the concentration range of $0.17-4.8 \mathrm{mmol} / \mathrm{L}$. The CL intensity increased with increasing fluorescer concentration until $3.2 \mathrm{mmol} / \mathrm{L}$, after which any further increase in fluorescer concentration was found to have no significant effect on PO-CL intensity. As such, $3.2 \mathrm{mmol} / \mathrm{L}$ was selected as the optimum fluorescer concentration.

\section{Calibration curve and performance characteristics}

Under the optimum conditions, a calibration curve was constructed by measuring the difference in CL intensities $(\triangle C L)$ in the presence and absence of a CA standard solution. The method provided satisfactory linearity. The relative standard deviation (RSD \%) was estimated for solutions containing $1 \mu \mathrm{g} / \mathrm{mL}$ of CAs, measured in the same day $(n=5)$. Performance characteristics of the method are presented in Table 2.

Table 1 Final optimum values for the PO-CL method for the determination of CAs

\begin{tabular}{lcc}
\hline Parameter & $\begin{array}{c}\text { Range studied/ } \\
\mathrm{mmol} / \mathrm{L}\end{array}$ & $\begin{array}{c}\text { Optimized value/ } \\
\mathrm{mmol} / \mathrm{L}\end{array}$ \\
\hline TCPO & $0.17-3.0$ & 2.5 \\
Sodium salicylate & $0.1-1.0$ & 0.8 \\
$\mathrm{H}_{2} \mathrm{O}_{2}$ & $2-17$ & 13 \\
Fluorescer & $0.17-4.8$ & 3.2 \\
\hline
\end{tabular}

\section{Interference study}

In order to apply the developed method for determination of CAs in pharmaceutical formulations, the effects of some compounds commonly used as excipients in pharmaceutical formulations were assessed. A sample solution containing a fixed amount of CAs $(1 \mu \mathrm{g} / \mathrm{mL})$ and different concentrations of the interference compounds under evaluation were analyzed by the present method. A compound was considered as non-interfering if the analytical CL signal variation was $\pm 5 \%$ when compared to the analytical signal obtained in the absence of the referred compound. The results revealed 100-fold $\mathrm{Na}^{+}, \mathrm{K}^{+}, \mathrm{Mg}^{2+}, \mathrm{Cl}^{-}, \mathrm{NO}_{3}^{-}$; 50-fold $\mathrm{Ca}^{2+}, \mathrm{Cu}^{2+}, \mathrm{Ni}^{2+}, \mathrm{Zn}^{2+}$, glucose; 10-fold ascorbic acid, $\mathrm{Co}^{2+}$ at a relative mass ratio regarding $\mathrm{CAs}$ did not interfere. Therefore, it can be concluded that the proposed method shows selectivity for the determination of CAs in commercial pharmaceutical formulations.

\section{Analysis of pharmaceutical formulations}

The proposed method was applied to the determination of CAs in pharmaceutical formulations. The method was validated by comparing the obtained results with the declared nominal values. A Student's $t$-test was applied from which it was possible to conclude that no significant differences were observed from the results obtained by using the proposed method and those reported by the labels (Table 3 ). This also demonstrated that no significant effect on the CL signal was produced from the excipients and other compounds added to the analyzed drugs.

\section{Kinetic and possible mechanism}

The effects of each of the CAs on the CL profile and reaction kinetics were determined under pseudo-first-order condition with $\mathrm{H}_{2} \mathrm{O}_{2}$ in large excess over TCPO. In order to evaluate the kinetic data for the PO-CL system studied from the resulting CL intensity-time plots, a pooled intermediate model was used. ${ }^{32,38}$ According to this model, the CL reaction is simplified as:

$$
\mathrm{A} \stackrel{k_{\mathrm{r}}}{\longrightarrow} \mathrm{B} \stackrel{k_{\mathrm{f}}}{\longrightarrow} \mathrm{C}
$$

where $\mathrm{A}, \mathrm{B}$ and $\mathrm{C}$ represent pools of reactants, intermediates

Table 3 PO-CL determination of CAs in pharmaceutical formulations $(n=5)$

\begin{tabular}{ccccc}
\hline Sample & $\begin{array}{c}\text { Proposed } \\
\text { method }\end{array}$ & $\begin{array}{c}\text { Recovery, RSD, \% } \\
\%\end{array}$ & $\begin{array}{c}P \text { value } \\
(n=5)\end{array}$ & $(\alpha=0.05)$ \\
\hline $\begin{array}{c}\text { Dopamine injection } \\
(200 \mathrm{mg} / 5 \mathrm{~mL})\end{array}$ & $200.2 \mathrm{mg} / 5 \mathrm{~mL}$ & 100.1 & 2.3 & 0.35 \\
$\begin{array}{c}\text { Epinephrine injection } \\
(1 \mathrm{mg} / \mathrm{mL})\end{array}$ & $1.05 \mathrm{mg} / \mathrm{mL}$ & 105 & 3.4 & 0.54 \\
$\begin{array}{c}\text { Methyldopa tablet } \\
(250 \mathrm{mg})\end{array}$ & $248 \mathrm{mg}$ & 99.2 & 5.8 & 0.86 \\
\hline
\end{tabular}

Table 2 Performance characteristics of the CL method

\begin{tabular}{|c|c|c|c|c|c|}
\hline Sample & $\begin{array}{l}\text { Linear range/ } \\
\mu \mathrm{g} \mathrm{mL}^{-1}\end{array}$ & Equation $(n=3)^{\mathrm{a}}$ & $R^{2}$ & $\begin{array}{c}\mathrm{RSD}(1 \mu \mathrm{g} / \mathrm{mL}) \\
(n=5)\end{array}$ & $\begin{array}{l}\text { Detection limit }{ }^{\mathrm{b}} / \\
\mu \mathrm{g} \mathrm{mL}^{-1}\end{array}$ \\
\hline Dopamine & $0.5-12.7$ & $\Delta C L=58.24 x+96.5$ & 0.997 & 1.9 & 0.30 \\
\hline Epinephrine & $0.06-1.83$ & $\Delta C L=581.55 x+68.1$ & 0.995 & 2.5 & 0.03 \\
\hline Methyldopa & $0.069-3.52$ & $\Delta C L=441.63 x+332.4$ & 0.999 & 5.2 & 0.04 \\
\hline
\end{tabular}

a. $\Delta C L=$ difference in CL intensities in the presence and absence of CAs, $x=$ sample concentration $(\mu \mathrm{g} / \mathrm{mL})$. b. $S / N=3$. 


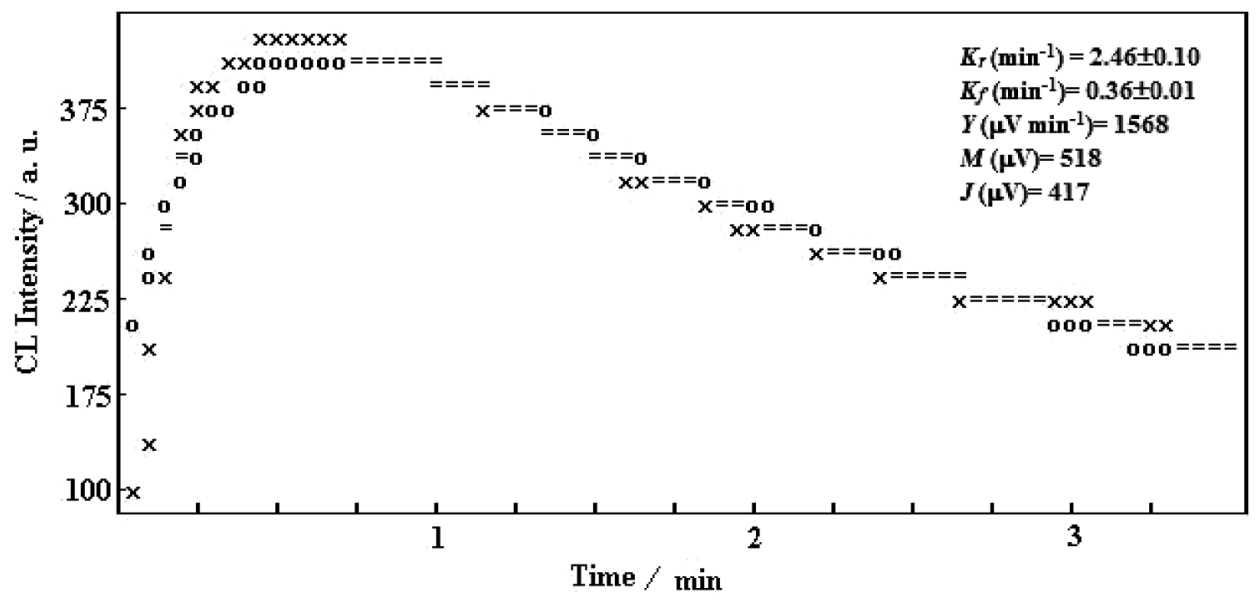

Fig. 3 Typical computer fitting of the CL intensity-time plot for the TCPO- $\mathrm{H}_{2} \mathrm{O}_{2}$-fluorescer-SS system $\left(2.5 \mathrm{mmol} / \mathrm{L} \quad \mathrm{TCPO}, 13 \mathrm{mmol} / \mathrm{L} \quad \mathrm{H}_{2} \mathrm{O}_{2}, 0.8 \mathrm{mmol} / \mathrm{L} \quad \mathrm{SS}, 3.2 \mathrm{mmol} / \mathrm{L}\right.$ fluorescer, $6.7 \times$ $10^{-2} \mathrm{mmol} / \mathrm{L} \mathrm{DA}$ ). ( $\times$ ) experimental point; (o) calculated point; (=) experimental and calculated points are the same within the resolution of the plot.

Table 4 CL parameters evaluated from computer fitting of the CL intensity-time plots for TCPO- $\mathrm{H}_{2} \mathrm{O}_{2}$-fluorescer-SS system in the absence and presence of various concentrations of CAs: $2.5 \mathrm{mmol} / \mathrm{L} \mathrm{TCPO}, 13 \mathrm{mmol} / \mathrm{L} \mathrm{H} \mathrm{H}_{2} \mathrm{O}_{2}, 0.8 \mathrm{mmol} / \mathrm{L} \mathrm{SS}, 3.2 \mathrm{mmol} / \mathrm{L}$ fluorescer

\begin{tabular}{|c|c|c|c|c|c|c|c|c|}
\hline CAs & $\begin{array}{c}\text { Concentration/ } \\
\mu \mathrm{mol} / \mathrm{L}\end{array}$ & $k_{\mathrm{r}} / \mathrm{min}^{-1}$ & $k_{\mathrm{f}} / \mathrm{min}^{-1}$ & $M / \mu \mathrm{V}$ & $J / \mu \mathrm{V}$ & $I / \mu \mathrm{V}$ & $T_{\max } / \min$ & $Y / \mu \mathrm{V} \min ^{-1}$ \\
\hline \multirow[t]{8}{*}{ DA } & 0 & $6.03 \pm 0.11$ & $1.18 \pm 0.01$ & 1506 & 1090 & 990 & 0.29 & 1244 \\
\hline & 3.3 & $4.42 \pm 0.07$ & $0.86 \pm 0.01$ & 1468 & 964 & 886 & 0.41 & 1397 \\
\hline & 8.3 & $4.19 \pm 0.10$ & $0.76 \pm 0.01$ & 1251 & 930 & 883 & 0.43 & 1413 \\
\hline & 16.7 & $3.89 \pm 0.10$ & $0.63 \pm 0.01$ & 1140 & 849 & 832 & 0.44 & 1449 \\
\hline & 33.0 & $3.25 \pm 0.10$ & $0.54 \pm 0.02$ & 899 & 680 & 687 & 0.46 & 1492 \\
\hline & 50.0 & $3.02 \pm 0.09$ & $0.42 \pm 0.01$ & 614 & 533 & 512 & 0.46 & 1529 \\
\hline & 67.0 & $2.46 \pm 0.10$ & $0.36 \pm 0.01$ & 518 & 417 & 396 & 0.47 & 1568 \\
\hline & 83.0 & $2.02 \pm 0.09$ & $0.28 \pm 0.01$ & 427 & 250 & 229 & 0.52 & 1598 \\
\hline \multirow[t]{8}{*}{$\mathrm{E}$} & 0 & $6.03 \pm 0.11$ & $1.18 \pm 0.01$ & 1506 & 1090 & 990 & 0.29 & 1244 \\
\hline & 0.33 & $5.00 \pm 0.11$ & $2.15 \pm 0.02$ & 1944 & 1178 & 1162 & 0.36 & 1187 \\
\hline & 1.67 & $4.89 \pm 0.07$ & $2.27 \pm 0.01$ & 2435 & 1341 & 1301 & 0.37 & 1136 \\
\hline & 3.30 & $4.25 \pm 0.10$ & $2.35 \pm 0.01$ & 3227 & 1500 & 1480 & 0.39 & 1121 \\
\hline & 5.00 & $4.12 \pm 0.10$ & $2.37 \pm 0.01$ & 3612 & 1715 & 1765 & 0.40 & 1075 \\
\hline & 6.70 & $3.76 \pm 0.10$ & $2.41 \pm 0.02$ & 3902 & 1910 & 1879 & 0.41 & 1012 \\
\hline & 8.30 & $3.24 \pm 0.09$ & $2.47 \pm 0.01$ & 4225 & 1999 & 2020 & 0.42 & 974 \\
\hline & 10.0 & $2.92 \pm 0.10$ & $2.53 \pm 0.01$ & 5680 & 2225 & 2203 & 0.42 & 924 \\
\hline \multirow[t]{9}{*}{ MD } & 0 & $6.03 \pm 0.11$ & $1.18 \pm 0.01$ & 1506 & 1090 & 990 & 0.29 & 1244 \\
\hline & 0.33 & $5.00 \pm 0.11$ & $2.25 \pm 0.02$ & 2012 & 1430 & 1398 & 0.35 & 1154 \\
\hline & 1.60 & $4.87 \pm 0.07$ & $2.29 \pm 0.01$ & 2680 & 1592 & 1573 & 0.36 & 1128 \\
\hline & 3.30 & $4.23 \pm 0.10$ & $2.38 \pm 0.01$ & 3350 & 1750 & 1702 & 0.36 & 1111 \\
\hline & 5.00 & $4.09 \pm 0.10$ & $2.44 \pm 0.01$ & 3825 & 1877 & 1822 & 0.37 & 1068 \\
\hline & 6.70 & $3.77 \pm 0.10$ & $2.49 \pm 0.02$ & 4012 & 2030 & 2002 & 0.38 & 1007 \\
\hline & 8.30 & $3.20 \pm 0.09$ & $2.52 \pm 0.01$ & 4480 & 2212 & 2265 & 0.38 & 978 \\
\hline & 13.3 & $2.91 \pm 0.10$ & $2.56 \pm 0.01$ & 5091 & 2660 & 2790 & 0.40 & 952 \\
\hline & 16.7 & $2.93 \pm 0.10$ & $2.59 \pm 0.01$ & 5930 & 2980 & 2958 & 0.40 & 928 \\
\hline
\end{tabular}

Statistical parameters $R^{2}=0.996 F=5586.157$ correlation is significant at the 0.01 level.

and products, respectively, and both reaction steps designated by the rate constants $k_{\mathrm{r}}$ and $k_{\mathrm{f}}$ are irreversible first-order reactions. The integrated rate equation for the CL intensity versus time is:

$$
I_{\mathrm{t}}=\left[\frac{M k_{\mathrm{r}}}{k_{\mathrm{f}}-k_{\mathrm{r}}}\right]\left[\exp \left(-k_{\mathrm{r}} t\right)-\exp \left(-k_{\mathrm{f}} t\right)\right]
$$

Where $I_{\mathrm{t}}$ is the CL intensity at time $t, M$ is a theoretical maximum level of intensity if the reactants were entirely converted to a CL-generating material, and $k_{\mathrm{r}}$ and $k_{\mathrm{f}}$ the first- order rate constants for the rise and fall of the burst of CL, respectively. A further advantage of this model is that it not only allows the determination of parameters $M, k_{\mathrm{r}}$ and $k_{\mathrm{f}}$ but also permits an estimate of the intensity at maximum level $(J)$, the time of maximum intensity $\left(T_{\max }\right)$ and the total light yield $(Y)$, as follows:

$$
J=M\left(\frac{k_{\mathrm{f}}}{k_{\mathrm{r}}}\right)^{\left[k_{\mathrm{f}} /\left(k_{\mathrm{r}}-k_{\mathrm{f}}\right)\right]}
$$



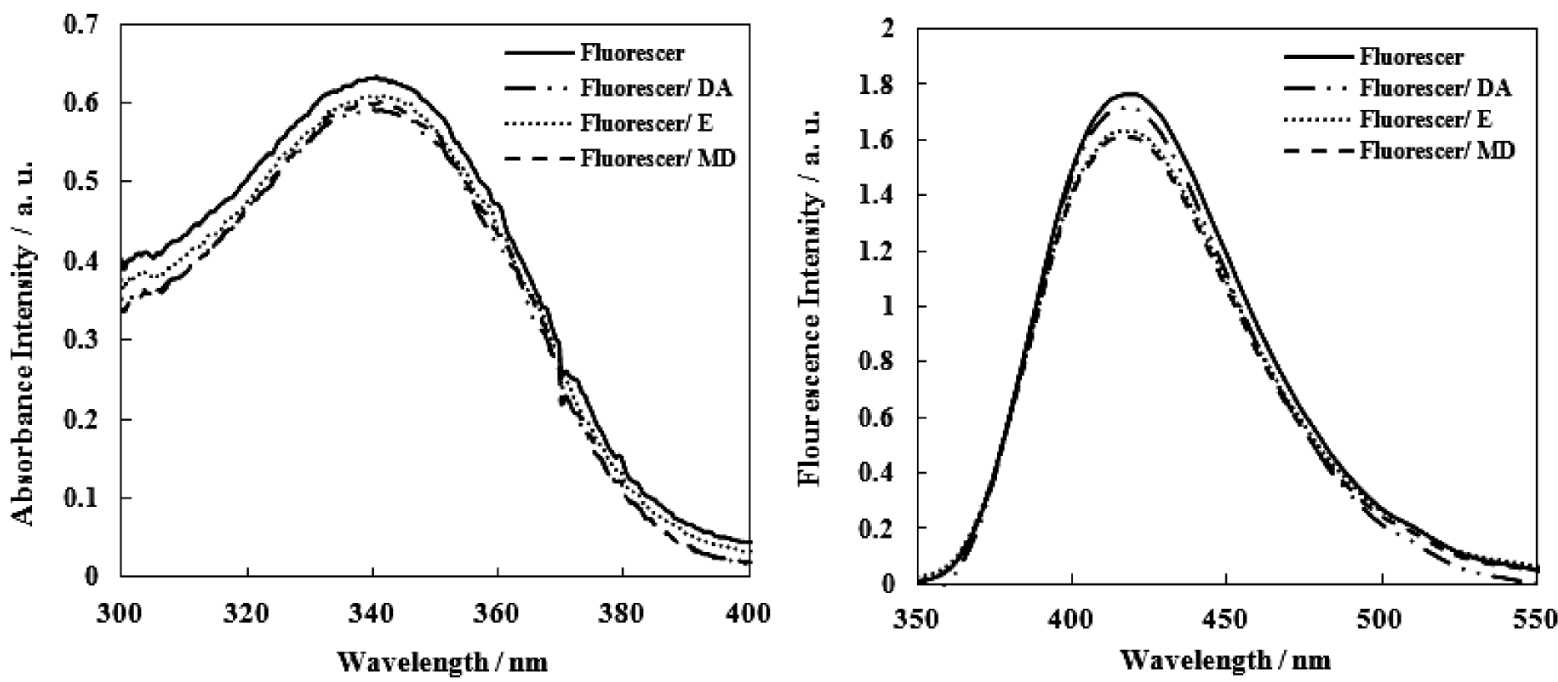

Fig. 4 Fluorescence and absorbance spectra of $3.2 \mathrm{mmol} / \mathrm{L}$ fluorescer in the absence and presence of $3.3 \times 10^{-2} \mathrm{mmol} / \mathrm{L}$ CAs.

$$
\begin{aligned}
& T_{\max }=\frac{\ln \left(k_{\mathrm{f}} / k_{\mathrm{r}}\right)}{k_{\mathrm{f}}-k_{\mathrm{r}}} \\
& Y=\int_{0}^{\infty} I_{\mathrm{t}} \mathrm{d} t=\frac{M}{k_{\mathrm{f}}}
\end{aligned}
$$

In this work, a non-linear least-squares curve fitting program KINFIT $^{39}$ was used to evaluate the $M, k_{\mathrm{r}}$ and $k_{\mathrm{f}}$ values from the corresponding CL intensity-time plots. A typical computer fit of the CL intensity time plots is shown in Fig. 3. As seen from this figure, there is a good agreement between the theoretical and experimental data that confirms the proposed model. The other parameters $J, T_{\max }$ and $Y$ were then evaluated from Eqs. (3) to (5) using the $k_{\mathrm{r}}, k_{\mathrm{f}}$ and $M$ values. The kinetic parameters thus obtained for all experiments carried out are summarized in Table 4. The experimental values of maximum CL intensity (I) was extracted from CL intensity-time plots for comparison. The statistical results $\left(R^{2}\right.$ and $\left.F\right)$ obtained by application of SPSS indicate that there is a satisfactory agreement between the calculated $(J)$ and experimental $(I)$ values of intensity at the maximum CL (Table 4). Results indicated that the rise rate constants $\left(k_{\mathrm{r}}\right)$ decreased in the presence of DA, E and MD; on the other hand, the fall rate constants $\left(k_{\mathrm{f}}\right)$ decreased in the presence of DA and increased in the presence of MD and E. The data are clearly in support of quenching effects of DA and strong enhancing effects of $\mathrm{MD}$ and $\mathrm{E}$ on the $\mathrm{TCPO}-\mathrm{H}_{2} \mathrm{O}_{2-}$ fluorescer chemiluminscence system. This result is similar to the result studied by Jonsson and Irgum. ${ }^{40}$

To clarify the CL mechanism of the present system, the fluorescence and UV-vis absorption spectra of the fluorescer in the absence and presence of CAs were carried out. All spectra had the same maximum emission wavelength at about $420 \mathrm{~nm}$. The presence of CAs produced no obvious difference compared with the fluorescence and absorbance spectra of fluorescer. The fluorescence and absorption intensity of fluorescer indicated no obvious interaction occurred between fluorescer and CAs (Fig. 4).

Therefore, the crucial step in quenching and enhancing the luminescence was assumed to be the reaction of the CAs with the highly energetic intermediate (1,2-dioxetanedione), and not a reaction with the fluorescer. The enhancement of CL intensity was attributed to the formation of a more stable structure for the 1,2-dioxetanedione by $\mathrm{E}$ and $\mathrm{MD}$, whereas the $\mathrm{CL}$ inhibition was attributed to the decomposition by DA to give CL products.

\section{Conclusions}

For the first time, a PO-CL method in the presence of a novel fluorescer, furandicarboxylate derivative, was developed based on the quenching effect of DA and enhancing effect of $\mathrm{E}$ and $\mathrm{MD}$ on a TCPO- $\mathrm{H}_{2} \mathrm{O}_{2}$-fluorescer-SS CL system. Compared with other common methods, the proposed method is simple, cheap, sensitive, rapid, and suitable for analysis and can be applied to the determination of those three CAs derivatives in their pharmaceutical preparations with satisfactory results. Based on the $\mathrm{CL}$ and fluorescence spectrum and kinetic data, we discussed the possible mechanism of TCPO- $\mathrm{H}_{2} \mathrm{O}_{2}$-fluorescer$\mathrm{SS} C \mathrm{~L}$ in the presence of a new fluorescer.

\section{References}

1. B. B. Hoffman and R. J. Lefkowitz, in "The Pharmacological Basis of Therapeutics", ed. A. G. Gilman, 9th ed., 1996, McGraw-Hill, New York, 211.

2. O. Hornykiewicz, J. Neural. Transm., 2006, 70, 9.

3. P. Nagaraja, R. A. Vasantha, and K. R. Sunitha, Talanta, 2001, 55, 1039.

4. L. C. Vieira and O. F. Filho, Talanta, 1998, 46, 559.

5. A. Ormazabal, A. Garcia-Cazorla, Y. Fernández, E. Fernández-Álvarez, J. Campistol, and R. Artuch, J. Neurosci. Methods, 2005, 142, 153.

6. L. Liu, Q. Li, N. Li, J. Ling, R. Liu, Y. Wang, L. Sun, X. H. Chen, and K. Bi, J. Sep. Sci., 2011, 34, 1198.

7. M. Zydroń, J. Baranowski, J. Białkowski, and I. Baranowska, Sep. Sci. Technol., 2005, 40, 3137.

8. M. A. Fotopoulou and P. C. Ioannou, Anal. Chim. Acta, 2002, 462, 179.

9. Z. Guo and S. Dong, Electroanalysis, 2005, 17, 7.

10. A. Vaarmann, A. Kask, and U. Maeorg, J. Chromatogr., B, 2002, 769, 145.

11. Q. Gu, X. Shi, P. Yin, P. Gao, X. Lu, and G. Xu, Anal. Chim. Acta, 2008, 609, 192. 
12. E. Nalewajko, A. Wiszowata, and A. Kojlo, J. Pharm. Biomed. Anal., 2007, 43, 1673.

13. G. J. Chou, G. F. Zhang, and H. Y. Chen, Anal. Chim. Acta 2002, 463, 257.

14. E. Nalewajko, R. Bort Ramirez, and A. Kojlo, J. Pharm. Biomed. Anal., 2004, 36, 219.

15. S. Wang, L. Du, L. Wang, and H. Zhuang, Anal. Sci., 2004, 20,315.

16. Y. Sun, Y. Tang, X. Zheng, H. Yao, and Z. Xu, Anal. Lett., 2004, 37, 2445.

17. H. Yao, Y. Sun, X. Lin, J. Cheng, and L. Huang, Luminescence, 2006, 21, 112.

18. C. Yu, Y. Tang, X. Han, and X. Zheng, Anal. Sci., 2006, 22, 25.

19. Y. C. Chen and W. Y. Lin, Luminescence, 2010, 25, 43.

20. F. N. Chen, Y. X. Zhang, and Z. J. Zhang, Chin. J. Chem., 2007, 25, 942 .

21. E. Nalewajko, A. Wiszowata, and A. Kojlo, J. Pharm. Biomed. Anal., 2007, 43, 1673.

22. Y. M. Liu, C. Q. Wang, H. B. Mu, J. T. Cao, and Y. L. Zheng, Electrophoresis, 2007, 28, 1937.

23. H. C. Tsai and C. W. Whang, Electrophoresis, 1999, 20, 2533.

24. Y. Hu, X. Li, and Z. Pang, J. Chromatogr., A, 2005, 1091, 194.

25. W. W. He, X. W. Zhou, and J. Q. Lu, J. Chromatogr., A, 2006, 1131, 289.

26. M. M. Rauhut, Acc. Chem. Res., 1969, 2, 80.

27. K. W. Sigvardson, J. M. Kennish, and J. W. Birks, Anal.
Chem., 1984, 56, 1096.

28. A. G. Hadd, A. L. Robinson, K. L. Rowlen, and J. W. Birks, J. Org. Chem., 1998, 63, 3023.

29. M. Stigbrand, E. Ponten, and K. Irgum, Anal. Chem., 1994, 66, 1766.

30. J. Motoyoshiya, N. Sakai, M. Imai, Y. Yamaguchi, R. Koike, Y. Takaguchi, and H. Aoyama, J. Org. Chem., 2002, 67, 7314.

31. L. H. Catalani and T. Wilson, J. Am. Chem. Soc., 1989, 111, 2633.

32. A. G. Hadd, A. Seeber, and J. W. Birks, J. Org. Chem., 2000, 65, 2675.

33. M. Shamsipur, M. J. Chaichi, and A. R. Karami, Spectrochim. Acta, Part A, 2003, 59, 511.

34. M. Shamsipur, A. Yeganeh-Faal, M. J. Chaichi, M. Tajbakhsh, and A. Parach, Specrochim. Acta, Part A, 2007, 66, 546.

35. A. Samadi-Maybodi, R. Akhoondi, and M. J. Chaich, J. Fluoresc., 2010, 20, 671

36. K. Zargoosh, M. J. Chaichi, S. Asghari, M. Qandalee, and M. Shamsipur, J. Iran. Chem. Soc., 2010, 7, 376.

37. S. Asghari and M. Qandalee, Acta Chim. Slov., 2007, 54, 638.

38. M. Orlovic, R. L. Schowen, R. S. Givens, F. Alvarez, B. Matuszewski, and N. Parekh, J. Org. Chem., 1989, 54, 3606.

39. J. L. Dye and V. A. Nicely, J. Chem. Educ., 1971, 48, 443. 40. T. Jonsson and K. Irgum, Anal. Chem., 2000, 72, 1373. 